studied even approaches that ultimately obtainable. Although the $D$ - and L-methylated derivatives resemble each other in contour more than do $D$ and L-fucose, it cannot be assumed that they are identical. It would be of interest to obtain by immunization homologous antibody with specificities directed against the $D$ - and L-methylated fucoses and to determine whether the structural similarities in Fig. 1 used in the explanation of these cross- reaction studies would hold for an homologous antigen-antibody system.

This work is supported by the National Science Foundation (G-18727) and the Office of Naval Research.

\section{REFERENCE}

Springer, G. F. \& Williamson, P. (1962). Biochem. J. 85, 282.

\title{
Studies on Isocitrate Oxidation in Mitochondria of Normal Rat Liver and Azo-Dye-Induced Hepatomas
}

\author{
By A. O. HAWTREY \\ National Chemical Research Laboratory, South African Council for Scientific and Industrial Research, \\ Pretoria, South Africa
}

(Received 8 May 1962)

Previous studies on isocitrate oxidation in normal rat-liver mitochondria have resulted in a controversy about the cofactor requirement and pathway of such oxidation. Kaplan, Swartz, Frech \& Ciotti (1956) as well as Purvis $(1958 a, b)$ have provided considerable evidence to indicate that the oxidation of isocitrate is NADP-dependent, and that the primary dehydrogenase reaction is followed by a transfer of electrons via a transhydrogenase enzyme to NAD, which is in turn linked through a cytochrome system to oxygen.

On the other hand, Ernster (1959) maintains that a NAD-dependent isocitrate dehydrogenase is also present, and has recently shown (Ernster \& Glasky, 1960) that, in pyridine nucleotide-depleted rat-liver mitochondria, isocitrate can be oxidized aerobically via a NAD-linked and NADPindependent pathway at a rate similar to that observed for isocitrate oxidation in intact mitochondria.

In view of these controversial findings, it was considered of importance to re-investigate the problem of isocitrate oxidation in normal rat-liver mitochondria, and the results of such research are reported in this paper.

Certain experiments on the oxidation of isocitrate in rat-hepatoma mitochondria induced by 4dimethylamino-3'-methylazobenzene and 4-dimethylaminoazobenzene are also reported, and these results, as well as those on the normal ratliver mitochondria, are contrasted with the findings of Hawtrey \& Silk $(1960,1961)$ on the oxidation of isocitrate in Ehrlich ascites-tumour-cell mitochondria.
Vignais \& Vignais (1961) have reported that the oxidation of isocitrate by pyridine nucleotidedepleted rat-liver mitochondria could be restored by NAD or NADP. Results in this paper support these findings, but differ in certain aspects, which are more fully dealt with in the Discussion.

\section{MATERIALS AND METHODS}

Male and female albino rats (wt. 200-250 g.) of the Wistar strain were provided by the National Nutrition Research Institute, Pretoria. The animals were housed in wire cages at $20^{\circ}$ and fed $a d l i b$. on the Institute's stock diet (protein, 20\%; ash, 7.4\%; main component: maize meal, $56 \%$ ) and tap water. The 4-dimethylamino- $3^{\prime}$-methylazobenzene-induced hepatoma was obtained from male rats of the above strain which had been fed on the stock diet containing $0.054 \%$ of the dye for a period of 8-9 months. The 4-dimethylaminoazobenzene-induced hepatoma was obtained from rats kindly supplied by Professor J. Gillman of the University of Witwatersrand, Johannesburg. Fully developed tumours induced by the feeding of azo dyes were grossly necrotic and gave poor results. All experiments reported were therefore carried out with hepatoma material contaminated to a slight extent with normal liver tissue.

Both the source and method of assay of the following materials have been described by Hawtrey \& Silk (1961): hexokinase, cytochrome c, AMP, ADP, Amytal [sodium 5-ethyl-5-(3-methylbutyl)barbiturate], antimycin A, DLisocitrate, nicotinamide, 2,6-dichlorophenol-indophenol and digitonin. NAD and NADP were supplied by C. F. Boehringer und Soehne, Germany, and assayed by the cyanide-addition method of Ciotti \& Kaplan (1957). Reduced NADP was also obtained from C. F. Boehringer und Soehne and its purity determined by measurement of $E$ at $340 \mathrm{~m} \mu$, with a millimolar extinction coefficient of $6 \cdot 3$. 
Vitamin $K_{1}$, vitamin $K_{8}$ (menadione) and neotetrazolium chloride were supplied by Nutritional Biochemicals Corp., Ohio, U.S.A., and used as such. 4-Dimethylamino-3'-methylazobenzene (m.p. 120.4-121.2 ${ }^{\circ}$ ) and 4dimethylaminoazobenzene were prepared according to Miller \& Miller (1948).

Yeast alcohol dehydrogenase and NADP-specific isocitrate dehydrogenase were obtained from C. F. Boehringer und Soehne. The alcohol-dehydrogenase enzyme was diluted before use, either with $10 \mathrm{~mm}$-tris- $\mathrm{HCl}(\mathrm{pH} \mathrm{10} \cdot 1)$ or with 10 mM-potassium phosphate ( $\mathrm{pH} \mathrm{7.5)} \mathrm{containing}$ $0.1 \%$ of ovalbumin. $\mathrm{NADPH}_{2}$-specific glutathione reductase was prepared from dried peas according to the method of Kaplan, Colowick \& Neufeld (1953). Ethanol was twice redistilled before use. All other reagents were of analytical grade.

Preparation of rat-liver and hepatoma mitochondria. Ratliver and hepatoma mitochondria were isolated in $0.44 \mathrm{M}$ sucrose according to the method of Dounce, Witter, Monty, Pate \& Cottone (1955), with slight modification, as follows. A rat-liver homogenate in $0.44 \mathrm{~m}$-sucrose (adjusted to $\mathrm{pH} 6.8$ with dilute citric acid) was centrifuged at $300 \mathrm{~g}$ for $20 \mathrm{~min}$. to remove nuclei and cell debris. The mitochondrial pellet was obtained from the supernatant by centrifuging at $10000 \mathrm{~g}$ for $10 \mathrm{~min}$. and washed successively in $0.44 \mathrm{M}$ - and $0.25 \mathrm{M}$-sucrose.

Depletion of mitochondria of pyridine nucleotides. Mitochondria isolated as described above were depleted of pyridine nucleotides as follows. A mitochondrial pellet obtained from $3.5 \mathrm{~g}$. of liver pulp was suspended in $11.0 \mathrm{ml}$. of $0.05 \mathrm{M}$-sucrose in $0.04 \mathrm{M}$-potassium phosphate $(\mathrm{pH} \mathrm{7.4)}$ by gentle homogenization with a small Dounce homogenizer. The suspension was then shaken on a Warburg bath at $30^{\circ}$ under aerobic conditions for $\mathbf{7 5} \mathrm{min}$. After depletion, the suspension was either stored in ice or centrifuged at $10000 \mathrm{~g}$ for $10 \mathrm{~min}$. and the resulting pellet resuspended in $0 \cdot 25 \mathrm{M}$-sucrose.

Measurement of oxygen uptake. This was carried out in Warburg manometers at $30^{\circ}$ as described by Hawtrey \& Silk (1961), except that the composition of the reaction medium was as indicated in the appropriate Tables.

Spectrophotometric assays. Measurements with 2,6dichlorophenol-indophenol or cytochrome $c$ as electron acceptor, as well as measurement of reduced NAD or NADP, was carried out in $1 \mathrm{~cm}$. cuvettes with a Zeiss spectrophotometer at room temperature. Reduction of 2,6-dichlorophenol-indophenol was followed at $600 \mathrm{~m} \mu$, and reduction of cytochrome $c$ at $550 \mathrm{~m} \mu$.

In the measurement of formazan production (reduced neotetrazolium chloride), reaction mixtures were first deproteinized by addition of $0.8 \mathrm{ml}$. of $10 \%$ trichloroacetic acid, and then extracted with ethyl acetate. The extracts containing the coloured formazan were read at $510 \mathrm{~m} \mu$.
Mitochondrial protein content. This was determined according to the biuret method of Cleland \& Slater (1953) with a bovine-albumin standard.

Determination of pyridine nucleotides in intact and depleted rat-liver mitochondria. The pyridine nucleotides, $\mathrm{NAD}, \mathrm{NADP}, \mathrm{NADH}_{2}$ and $\mathrm{NADPH}_{2}$, were determined by enzymic and fluorimetric methods applied to acid and alkaline extracts of mitochondria as described in detail by Purvis (1960).

\section{RESULTS}

Pyridine nucleotide contents of intact and depleted rat-liver mitochondria. Analyses for NAD, $\mathrm{NADP}, \mathrm{NADH}_{2}$ and $\mathrm{NADPH}_{2}$ present in intact and depleted rat-liver mitochondria were carried out to determine the effectiveness of the depletion procedure. Results for intact mitochondria (Table 1) parallel those of previous work (Purvis, 1960), and those for depleted particles show them to be essentially free of pyridine nucleotides. The concentrations of NADP and NAD found $(<0.1 \mu$ mole/g. of protein) are less than one-thousandth of the concentrations of added pyridine nucleotide required to give the effects observed in the experiments described below. Hence it is justifiable to conclude that these were not caused by residual endogenous cofactors.

Pyridine nucleotide as electron acceptor. Isocitrate-dehydrogenase activity with pyridine nucleotide as electron acceptor was measured spectrophotometrically at $340 \mathrm{~m} \mu$. No increase in $E$ was observed in depleted mitochondria in the absence of added pyridine nucleotide. The results in Fig. 1 show that in rat-liver mitochondria the isocitrate dehydrogenase was NADP-specific, whereas in the hepatoma activity was also observed with NAD as cofactor. Reduction of NAD by hepatoma mitochondria with isocitrate as substrate was initially rapid, but the rate decreased considerably after 1-2 min. This phenomenon was observed in a number of tumour preparations. On the other hand, reduction of NADP by the hepatoma mitochondria was rapid and linear with time. That the reduction of NADP and NAD by depleted rat-liver mitochondria in these experiments was a measure of isocitrate oxidation, and was not due largely to further oxidation of $\alpha$-oxoglutarate and other products formed as a result of the initial oxidation, was shown by the fact that, under the conditions of

Table 1. Concentration of pyridine nucleotides in intact and depleted rat-liver mitochondria

Figures in parentheses are those given by Purvis (1960).

Pyridine nucleotide ( $\mu$ moles/g. of mitochondrial protein)

$\begin{array}{lcccc}\text { Mitochondria } & \mathrm{NAD} & \mathrm{NADH}_{2} & \mathrm{NADP} & \mathrm{NADPH}_{2} \\ \text { Intact } & 1.69(1.51) & 1.30(1 \cdot 26) & 0.27(0.25) & \mathbf{3 . 5 2 ( 3 . 3 4 )} \\ \text { Depleted } & <0.1 & 0 & <0.1 & 0\end{array}$


reaction, depleted mitochondria did not reduce either NAD or NADP when $\alpha$-oxoglutarate was added as substrate. This was not solely due to formation of a complex of the $\alpha$-oxoglutarate with the KCN in the medium, since the final concentrations of KCN and $\alpha$-oxoglutarate were 1 and $2.5 \mathrm{~mm}$ respectively. It is suggested therefore that either a loss of cofactors or structural damage to the depleted particles is responsible for loss of $\alpha$-oxoglutarate oxidation.

Alternate inhibitors of electron transport acting between reduced NAD and oxygen were used in certain experiments, since $\mathrm{CN}^{-}$ion may have been inhibitory towards a NAD-linked dehydrogenase. The use of $1.8 \mathrm{~mm}$-Amytal, $1 \mathrm{~mm}$-azide and antimycin A (10 $\mu$ g.) as inhibitors of electron transport in the assay of normal rat-liver isocitrate-dehydro-

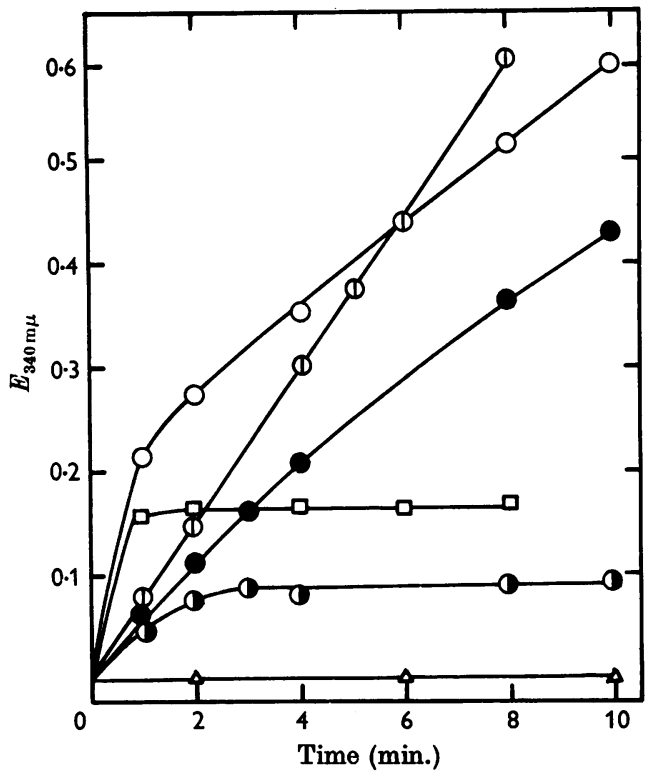

Fig. 1. Reduction of NAD and NADP by pyridine nucleotide-depleted mitochondria of rat liver and 4-dimethylamino-3'-methylazobenzene- and 4-dimethylaminoazobenzene-induced hepatomas. Each cuvette contained, in a final volume of $3.0 \mathrm{ml}$.: $0 \cdot 10 \mathrm{M}$-tris-acetate buffer ( $\mathrm{pH} \mathrm{7.4)}$; $1 \mathrm{~mm}-\mathrm{KCN}$; 3 mM- $\mathrm{MgCl}_{2} ; 20 \mathrm{~mm}$-nicotinamide; $2.5 \mathrm{~mm}$ DL-isocitrate (potassium salt, $\mathrm{pH} 7.4$ ); $0.24 \mu$ mole of NADP (in all preparations); $0.68 \mu$ mole of NAD for liver and 4dimethylaminoazobenzene-induced hepatoma preparations, $0.82 \mu$ mole of NAD for 4-dimethylamino-3'-methylazobenzene mitochondria ; mitochondrial protein (rat liver, $0.81 \mathrm{mg}$.; 4-dimethylaminoazobenzene-induced hepatoma, $0.75 \mathrm{mg}$.; 4-dimethylamino-3'-methylazobenzene-induced hepatoma, $0.81 \mathrm{mg}$.$) . Curves: NAD (\triangle)$ and NADP (D) with liver mitochondria; NAD (O) and NADP (O) with mitochondria of 4-dimethylaminoazobenzene-induced hepatoma; NAD ( $\square$ ) and NADP (O) with mitochondria of 4-dimethylamino-3'-methylazobenzene-induced hepatoma. genase activity with NAD as added electron acceptor failed to cause reduction of NAD.

The effect of $\mathrm{pH}$ on isocitrate-dehydrogenase activity in liver mitochondria with NADP as cofactor is shown in Fig. 2. The dehydrogenase was found to have a pH optimum of 8.1 in tris-acetate buffer. The effect of NADP concentration on the rate of reduction of NADP by this enzyme at pH 7.4 is shown in Fig. 3. The dehydrogenase was saturated at a concentration of $0.2 \mathrm{~mm}$-NADP.

2,6-Dichlorophenol-indophenol as electron acceptor. Results obtained with 2,6-dichlorophenolindophenol as electron acceptor are shown in Fig. 4. In the absence of added pyridine nucleotide, no reduction of the dye was observed. Ratliver mitochondria reduced the dye only in the presence of NADP as added cofactor, and an increase in the rate of dye reduction was observed when both NADP and NAD were present, indicating the participation of a transhydrogenase

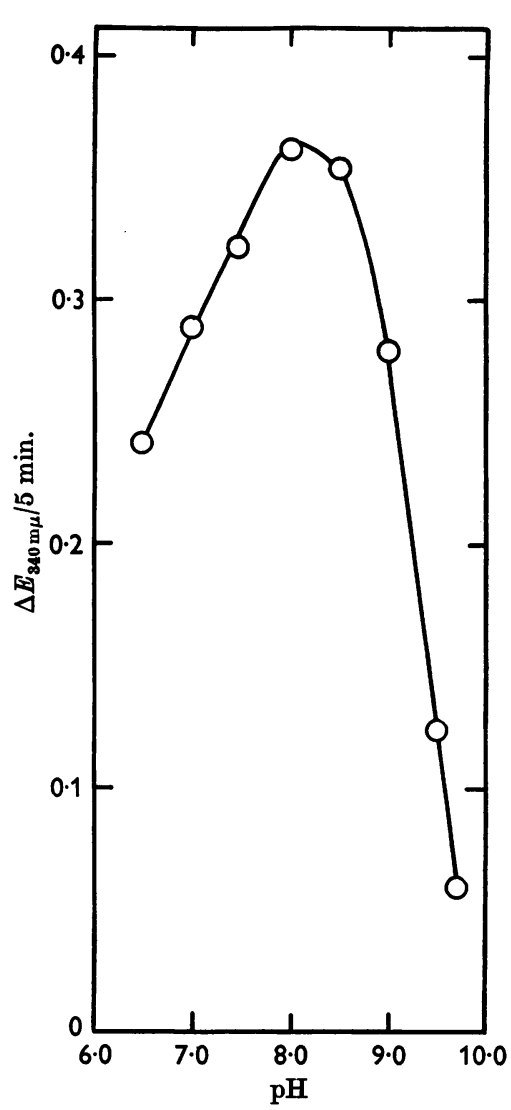

Fig. 2. Effect of pH on NADP-dependent isocitrate-dehydrogenase activity in rat-liver mitochondria. Reaction medium was as described for Fig. 1. Cuvettes contained $0.81 \mathrm{mg}$. of mitochondrial protein and $0.24 \mu \mathrm{mole}$ of NADP. 
system. In contrast, hepatoma mitochondria reduced 2,6-dichlorophenol-indophenol with either NADP or NAD as added cofactor. The rate of reaction, however, was greater with NADP.

Reduction of 2,6-dichlorophenol-indophenol by depleted rat-liver mitochondria with isocitrate and NADP was maximal at $0.18 \mathrm{~mm}-\mathrm{NADP}$ (Fig. 5), whereas the same reaction in 4-dimethylamino-3'methylazobenzene-induced-hepatoma mitochondria was found to be saturated at $0.20 \mathrm{~mm}-\mathrm{NADP}$ (Fig. 6). The effect of NADP concentration on this reaction was not measured in the hepatoma induced with 4-dimethylaminoazobenzene. The effect of concentration of NAD on 2,6-dichlorophenolindophenol reduction in the hepatoma mitochondria is shown in Fig. 7, where it is seen that the systems are saturated at $0.50 \mathrm{~mm}$-NAD (4-dimethylamino-3'-methylazobenzene) and $0.68 \mathrm{~mm}$ NAD (4-dimethylaminoazobenzene) respectively.

Competition experiments were carried out with rat-liver mitochondria to determine whether

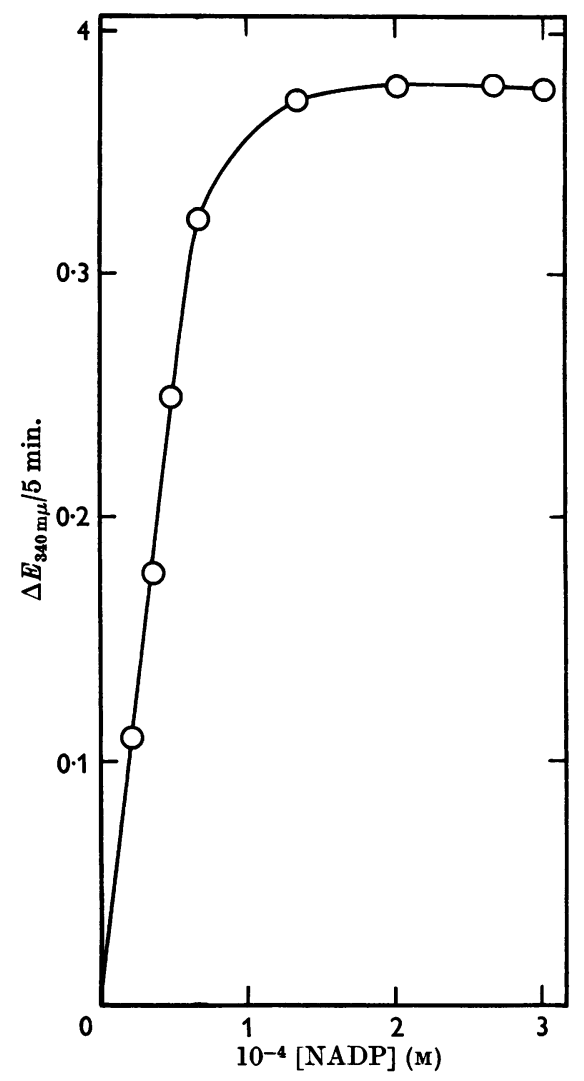

Fig. 3. Effect of concentration of NADP on the rate of isocitrate oxidation by rat-liver mitochondrial isocitrate dehydrogenase. Cuvettes contained $0.81 \mathrm{mg}$. of mitochondrial protein. reduced NADP generated by isocitrate oxidation and reduced NADP generated externally (chemically reduced) are oxidized via a common diaphorase system, or through separate diaphorases. The effect of reduced NADP concentration on 2,6dichlorophenol-indophenol reduction in depleted liver mitochondria is shown in Fig. 8. A concentration of $\mathbf{0 . 3 0}$ mM-reduced NADP was sufficient to saturate the system, and increasing the amount of reduced NADP beyond this value brought about inhibition of the reaction. Results in Table 2 illustrate the reduction of 2,6-dichlorophenolindophenol by rat-liver mitochondria with isocitrate + NADP, and reduced NADP, as substrates. Substrates and cofactors were present at saturating concentrations. It was observed that the rate of dye reduction with isocitrate + NADP + reduced NADP was greater than with either reduced

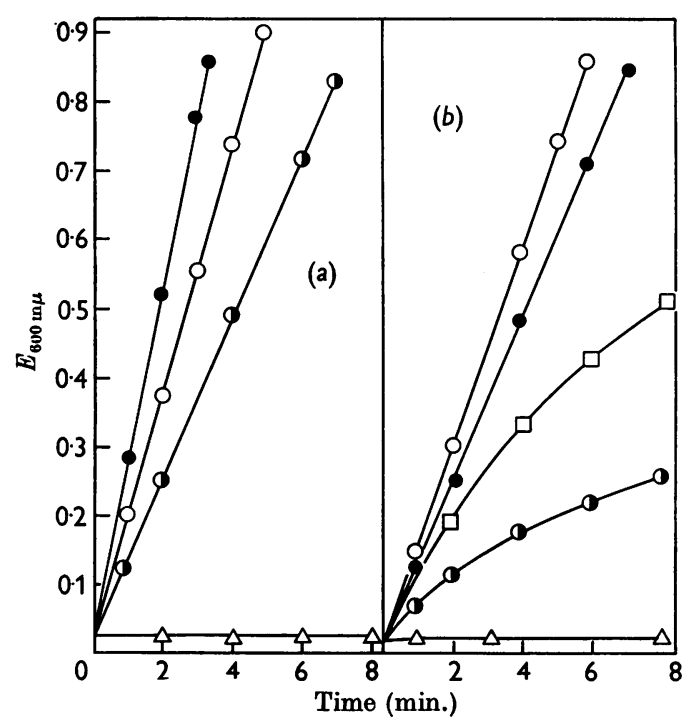

Fig. 4. Reduction of 2,6-dichlorophenol-indophenol by pyridine-nucleotide-depleted mitochondria of $(a)$ rat liver and (b) 4-dimethylamino-3'-methylazobenzene- and 4-dimethylaminoazobenzene-induced hepatomas. Each cuvette contained the basic medium given for Fig. 1, with isocitrate as substrate, and these extra additions: $36 \mu \mathrm{M}-2,6$-dichlorophenol-indophenol; $0 \cdot 24 \mu$ mole of NADP (in all preparations); NAD, $0.50 \mu$ mole (liver), $1.67 \mu$ moles (4-dimethylamino-3' methylazobenzene mitochondria), $0.68 \mu$ mole (4-dimethylaminoazobenzene mitochondria); mitochondrial protein (rat liver, 0.72-0.83 mg.; 4-dimethylaminoazobenzeneinduced hepatoma, $0.75 \mathrm{mg}$; ; 4-dimethylamino-3'-methylazobenzene-induced hepatoma, $0.81 \mathrm{mg}$.). Curves: (a) $\triangle$, NAD; O, NADP; $\odot, N A D P$ and Amytal; $\odot, N A D$ and NADP. (b) $\triangle$, Isocitrate; $\square, \mathrm{NAD}$, and $O$, NADP, with mitochondria of 4-dimethylamino-3'-methylazobenzeneinduced hepatoma; $\bigcirc, \mathrm{NAD}$, and $\bigcirc$, NADP, with mitochondria of 4-dimethylaminoazobenzene-induced hepatoma. 
NADP or isocitrate + NADP alone. This suggests the presence in rat-liver mitochondria of more than one diaphorase system associated with reducedNADP oxidation.

The effect of variation in $\mathrm{pH}$ on the NAD- and NADP-linked diaphorase systems associated with isocitrate oxidation in 4-dimethylamino-3'-methylazobenzene-induced-hepatoma mitochondria was measured in tris-acetate buffers with 2,6-dichlorophenol-indophenol as electron acceptor. Results in Fig. 9 show that the NAD-linked system has a pH optimum at $7 \cdot 2$ and the NADP-dependent diaphorase a $\mathrm{pH}$ optimum at $\mathbf{7 \cdot 5}$. To differentiate further between the NAD- and NADP-linked diaphorase systems in 4-dimethylamino-3'-methylazobenzene-induced-hepatoma mitochondria, the effect of aging on these systems was studied. Mitochondria that had been depleted of pyridine nucleotides were aged for $178 \mathrm{hr}$. at $0^{\circ}$ in $0.05 \mathrm{M}$ sucrose plus 0.04 M-potassium phosphate buffer,

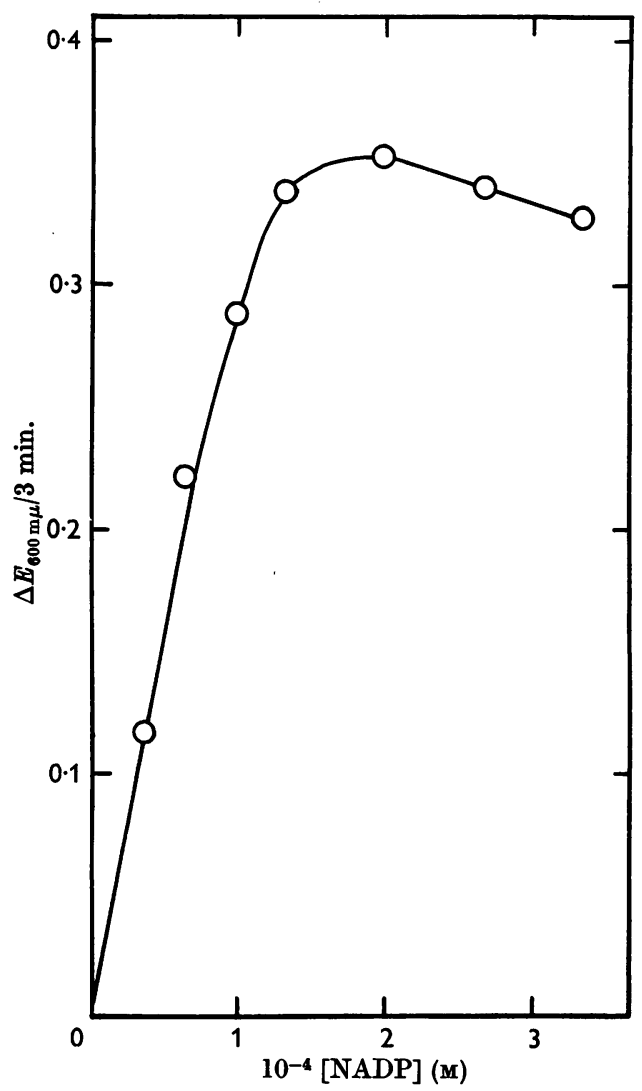

Fig. 5. Effect of added NADP on the rate of isocitrate oxidation in rat-liver mitochondria depleted of pyridine nucleotides, with 2,6-dichlorophenol-indophenol as electron acceptor. Cuvettes contained $0.77 \mathrm{mg}$. of mitochondrial protein.
$\mathrm{pH}$ 7.4. Samples of the mitochondrial suspension were removed after $24,68,92$ and $168 \mathrm{hr}$. for assay of diaphorase activity with 2,6-dichlorophenol-indophenol as electron acceptor. Results in Table 3 show that NADP-dependent isocitrate oxidation increased by approx. $47 \%$ on storage for $168 \mathrm{hr}$. at $0^{\circ}$, whereas that of the NAD-linked enzyme system decreased by approx. $47 \%$.

Cytochdrome c as electron acceptor. Studies with cytochrome $c$ as electron acceptor were carried out only with normal liver mitochondria and are reported in Table 4. The results obtained were similar to those with indophenol as electron acceptor, except that the rate of cytochrome $c$ reduction was much slower.

Oxygen as terminal electron acceptor. In the experiments with oxygen as terminal electron acceptor, pyridine nucleotide-depleted rat-liver mitochondria were centrifuged again as described in the Materials and Methods section and finally resuspended in cold $0.25 \mathrm{M}$-sucrose. Results in a medium containing phosphate buffer are shown in Table 5. The $q_{\mathrm{o}_{2}}$ of mitochondria aged for $60 \mathrm{~min}$. was 15.3 with $0.80 \mathrm{mM}-\mathrm{NAD}$ as cofactor, and 2.7 with $0.67 \mathrm{~mm}-\mathrm{NADP}$ as cofactor. Increasing the concentration of NAD to $1.60 \mathrm{~mm}$ raised the $q_{\mathrm{o}_{2}}$ to

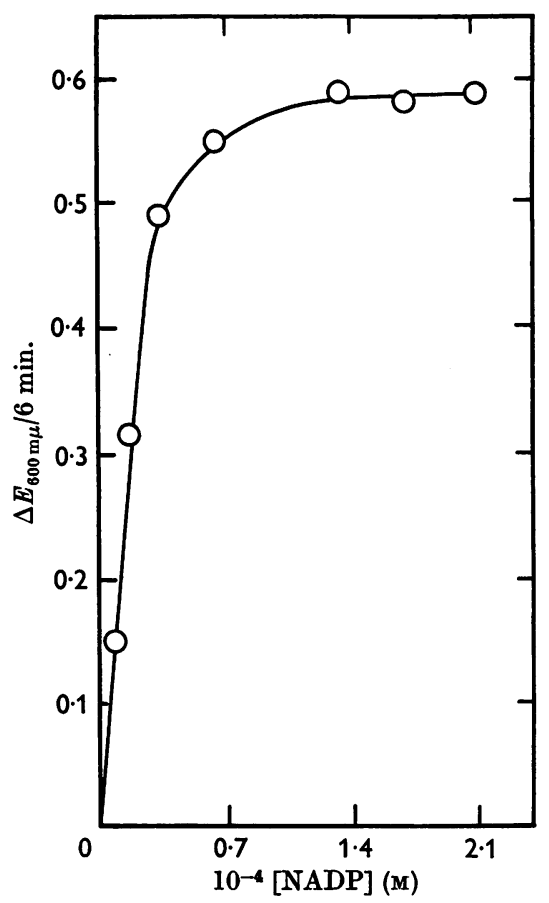

Fig. 6. Effect of added NADP on the rate of isocitrate oxidation in pyridine nucleotide-depleted mitochondria of 4-dimethylaminoazobenzene-induced hepatoma, with 2,6dichlorophenol-indophenol as electron acceptor. Cuvettes contained $0.75 \mathrm{mg}$. of mitochondrial protein. 
28.3. In experiments where both $\operatorname{NAD}(0.80 \mathrm{mM})$ and NADP $(0.67 \mathrm{~mm})$ were present, the $q_{0}$, was $27 \cdot 2$. Very similar results were obtained with mitochondria that had been depleted by aging for 80 min. (Table 5).

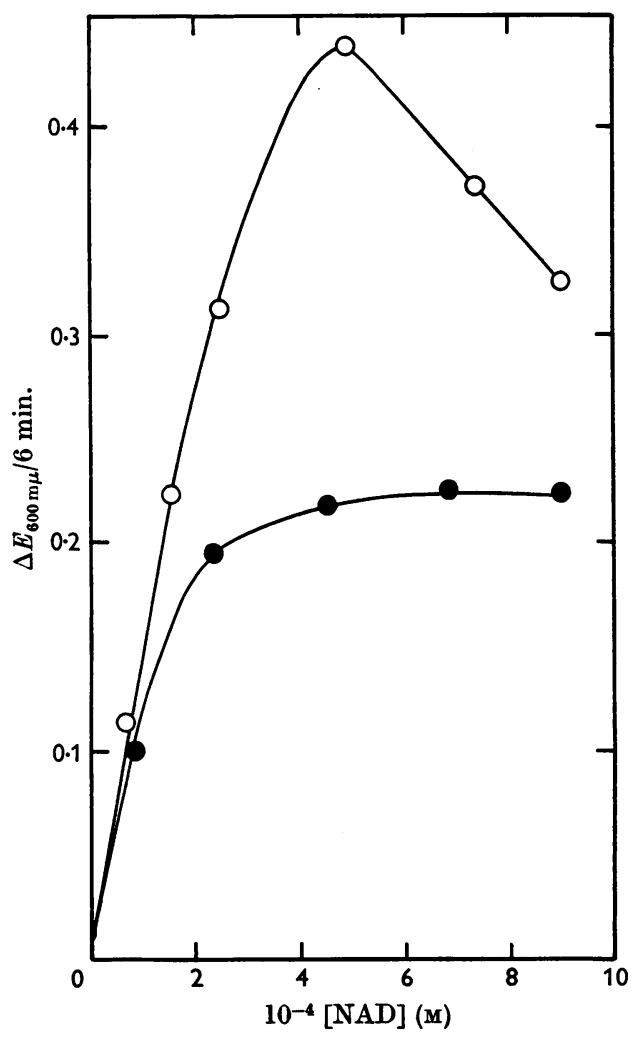

Fig. 7. Effect of concentration of NAD on isocitrate oxidation in pyridine nucleotide-depleted mitochondria of 4dimethylamino-3'-methylazobenzene- $(O)$ and 4-dimethylaminoazobenzene- (O) induced-hepatomas with 2,6dichlorophenol-indophenol as electron acceptor. Incubation medium and mitochondrial protein contents were as described for Fig. 1 .

\section{Table 2. Diaphorase activity of pyridine} nucleotide-depleted rat-liver mitochondria

Each curette contained the standard reaction medium given in Fig. 1. Concentrations of added cofactors are saturating (see Figs. 7 and 8). Isocitrate (pH 7.4), $2.5 \mathrm{~mm}$; $\mathrm{KCN}$, mM; 2,6-dichlorophenol-indophenol, $36 \mu \mathrm{M}$. Mitochondrial protein, $0.77 \mathrm{mg}$.

\section{System}

Reduced NADP (0.3 mM)

Isocitrate + NADP (0.2 mM)

Isocitrate + NADP $(0.2 \mathrm{~mm})+$ reduced NADP (0.3 $\mathrm{mm})$
Table 3. Effect of aging on NAD-dependent and NADP-dependent isocitrate-diaphorase activities of pyridine mucleotide-depleted hepatoma mitochondria

Experimental conditions and reaction medium were as described for Fig. 1. Mitochondria (from hepatoma induced by 4-dimethylamino-3'-methylazobenzene) were aged by storage in $0.05 \mathrm{M}$-sucrose plus $0.04 \mathrm{M}$-phosphate buffer, $\mathrm{pH} 7 \cdot 4$, at $0^{\circ}$ for the times shown. Cuvettes contained $0.81 \mathrm{mg}$. of mitochondrial protein and $0.21 \mu \mathrm{mole}$ of NADP or $0.74 \mu$ mole of NAD. The mitochondrial suspension was rehomogenized each time before assay.

\begin{tabular}{|c|c|c|}
\hline \multirow{2}{*}{$\begin{array}{l}\text { Time stored } \\
\text { at } 0^{\circ} \\
\text { (hr.) }\end{array}$} & \multicolumn{2}{|c|}{$\begin{array}{c}\Delta E_{600 \mathrm{mu}} / 10 \mathrm{~min} . \\
\text { (electron acceptor, } \\
\text { 2,6-dichlorophenol-indophenol) }\end{array}$} \\
\hline & NADP + isocitrate & NAD + isocitrate \\
\hline $\begin{array}{r}0 \\
24 \\
68 \\
92 \\
168\end{array}$ & $\begin{array}{l}1 \cdot 025 \\
1 \cdot 068 \\
1 \cdot 225 \\
1 \cdot 240 \\
1 \cdot 505\end{array}$ & $\begin{array}{l}0.452 \\
0.448 \\
0.392 \\
0.259 \\
0.240\end{array}$ \\
\hline
\end{tabular}

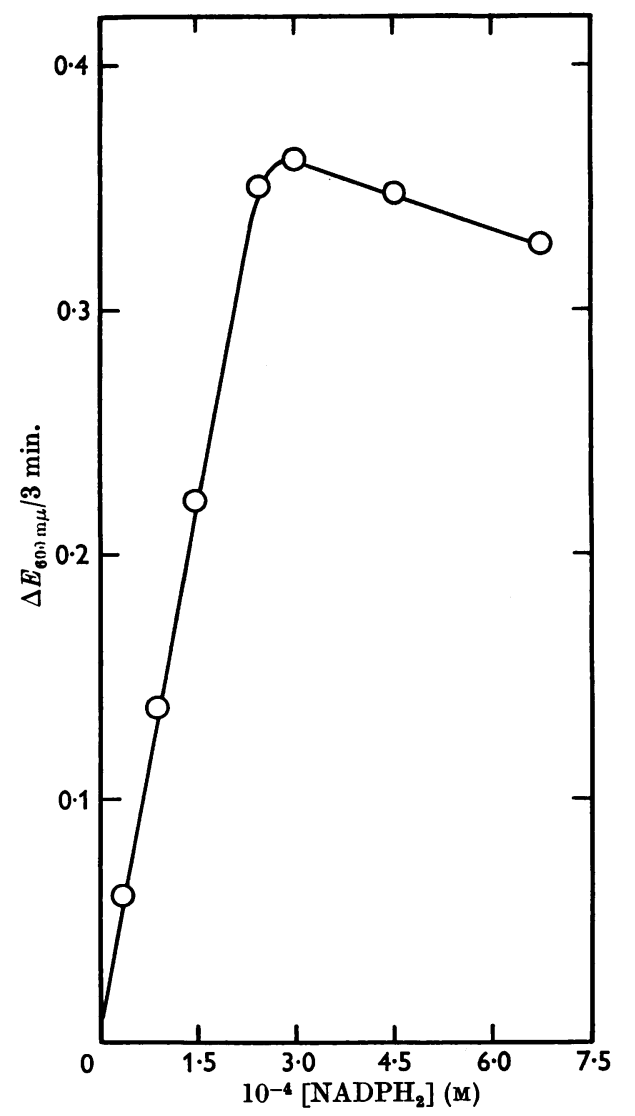

Fig. 8. Reduction of 2,6-dichlorophenol-indophenol by depleted rat-liver mitochondria with reduced NADP as substrate. Mitochondrial protein content, $0.77 \mathrm{mg}$. 
To determine the possible contribution of $\alpha$ oxoglutarate and other oxidation products of isocitrate to the oxygen uptake when isocitrate was used as substrate, the tests described in Table 6 were carried out. The results show that depleted rat-liver mitochondria are capable of oxidizing $\alpha$-oxoglutarate in the presence of added NAD and malonate, but at a considerably slower rate $\left(q_{0_{2}}, 4 \cdot 8\right)$ than isocitrate under the same conditions $\left(q_{0_{2}} 17 \cdot 5\right)$. It is therefore clear that at least $75 \%$ of the oxygen uptake occurring with isocitrate as substrate and NAD as cofactor is due to oxidation of isocitrate as such.

As a test for the intactness of rat-liver mitochondria depleted of pyridine nucleotides as described in the Materials and Methods section, certain experiments with citrate as substrate were carried out. A loss of citrate-oxidase activity would indicate considerable loss of protein from the mitochondria as well as possible damage to its phosphorylation properties. Results with citrate as substrate are reported in Table 5 . The $q_{\mathrm{o}_{2}}$ with 0.67 mM-NADP as cofactor was 2.2 , whereas with $0.80 \mathrm{mM}-\mathrm{NAD}$ it was 3.7. Addition of both cofactors together resulted in $q_{\mathrm{o}_{2}} 2 \cdot 6$. These results demonstrate that pyridine nucleotide-depleted rat-

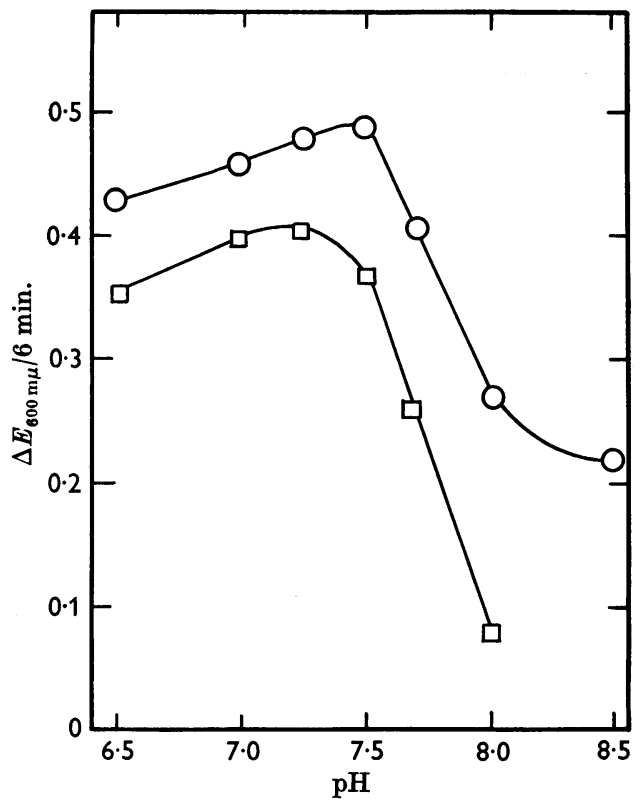

Fig. 9. Effect of variation in $\mathrm{pH}$ on the rate of isocitrate oxidation in depleted mitochondria of 4-dimethylamino-3' methylazobenzene-induced hepatoma with 2,6-dichlorophenol-indophenol as electron acceptor. Cuvettes contained the medium given in Fig. 1 and $0.81 \mathrm{mg}$. of mitochondrial protein. $O$, Isocitrate $+0 \cdot 36 \mu$ mole of NADP; $\square$, isocitrate $+1 \cdot 8 \mu$ moles of NAD.

liver mitochondria have lost the capacity to oxidize citrate.

In view of the finding that pyridine nucleotidedepleted rat-liver mitochondria oxidized isocitrate with NAD as added cofactor, and that the rate of oxidation was increased when NAD and NADP were present together, it was considered necessary to carry out further experiments aimed at determining whether or not the NAD- and NADP.

Table 4. Reduction of cytochrome c by pyridine nucleotide-depleted rat-liver mitochondria with isocitrate as substrate

Each cuvette contained the standard reaction medium given in Fig. 1. Cytochrome $c(40 \mu \mathrm{M})$ was present as terminal electron acceptor. Mitochondrial protein, $\mathbf{0 . 6 1} \mathrm{mg}$. $\Delta E_{550 \mathrm{~m} \mu} / \mathrm{min}$. (electron acceptor,

System

Isocitrate

Isocitrate $+0.15 \mathrm{~mm}-\mathrm{NAD}$

Isocitrate + 0.1 mM-NADP

Isocitrate + 0.1 mM-NADP +

0.15 mM-NAD

* Rates were linear for $2 \mathrm{~min}$. cytochrome c)

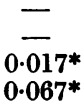

Table 5. Oxygen uptake of pyridine nucleotidedepleted rat-liver mitochondria in phosphate buffer

Each manometric flask contained the following, in a final volume of $2.0 \mathrm{ml}$.: $\mathrm{K}_{2} \mathrm{HPO}_{4}-\mathrm{KH}_{2} \mathrm{PO}_{4}$ buffer (pH 7.4), $45 \mathrm{mM}$; KCl, 7.5 mM; D-glucose, 37.5 mM; $\mathrm{MgCl}_{2}, 7.5 \mathrm{mM}$; ADP, 2 mм; AMP, 1 mм; EDTA (pH 7.4), 3 mм; sucrose, $47 \mathrm{mM}$ (includes sucrose of mitochondrial suspension); KF, $15 \mathrm{mM}$; nicotinamide, $20 \mathrm{mM}$; cytochrome c, $0.04 \mu \mathrm{M}$; DL-isocitrate (sodium salt), $10 \mathrm{mM}$, or citrate (sodium salt), $10 \mathrm{~mm}$; 1-1.4 mg. of crystalline hexokinase; mitochondrial suspension in 0.25 M-sucrose, 0.3 ml. Equilibration time, $8 \mathrm{~min}$. Mitochondria were depleted as described in the text. Intact rat-liver mitochondria without the addition of pyridine nucleotide gave $q_{\mathrm{O}_{2}} 48-50$ with isocitrate as substrate.

Citrate

$\begin{array}{cccc}\text { Substrate } & \text { Special additions } & \begin{array}{c}\text { Aged for } \\ 60 \text { min.* }\end{array} & \begin{array}{c}\text { Aged for } \\ 80 \text { min. }\end{array} \\ \text { Isocitrate } & - & - & - \\ & 0.33 \text { mM-NADP } & 1.8 & 2.1 \\ & 0.67 \text { mM-NADP } & 2.7 & 3.4 \\ & 0.80 \text { mM-NAD } & 15 \cdot 3 & 13.0 \\ & 1.60 \text { mM-NAD } & 28.3 & 26.1 \\ & 0.67 \text { mM-NADP }+ & 27.2 & 22.0 \\ \text { Citrate } & 0.80 \text { mM-NAD } & & - \\ & 0.67 \text { mM-NADP } & 2.2 & 1.3 \\ & 0.80 \text { mM-NAD } & 3.7 & 4.7 \\ & 0.67 \text { mM-NADP }+ & 2.6 & 3.8\end{array}$

* Each flask contained $5 \cdot 16 \mathrm{mg}$. of protein.

$\dagger$ Each flask contained $4.43 \mathrm{mg}$. of protein. 
dependent isocitrate-dehydrogenase systems are linked via separate or through a common cytochrome pathway to oxygen. As part of this further

Table 6. Oxidation of isocitrate and $\alpha$-oxoglutarate by pyridine nucleotide-depleted rat-liver mitochondria

The reaction medium was as described in Table 5. Each manometric flask contained $5 \cdot 1 \mathrm{mg}$. of mitochondrial protein. Incubation was for $20 \mathrm{~min}$. at $30^{\circ}$. DL-Isocitrate (sodium salt), $10 \mathrm{~mm}$; $\alpha$-oxoglutarate, $10 \mathrm{~mm}$.

\begin{tabular}{|c|c|}
\hline System & $\begin{array}{c}q_{\mathrm{o}_{2}}\left(\mu \mathrm{l} \text {. of } \mathrm{O}_{2} / \mathrm{mg} \text {. }\right. \\
\text { of protein } / \mathrm{hr} .)\end{array}$ \\
\hline Isocitrate & - \\
\hline Isocitrate + 1.8 mM-NAD & $21 \cdot 8$ \\
\hline $\begin{array}{l}\text { Isocitrate }+1.8 \mathrm{~mm}-\mathrm{NAD}+ \\
20 \mathrm{~mm}-\text { malonate }\end{array}$ & $17 \cdot 5$ \\
\hline$\alpha$-Oxoglutarate & $1 \cdot 3$ \\
\hline$\alpha$-Oxoglutarate +20 mm-malonate & $1 \cdot 1$ \\
\hline $\begin{array}{l}\alpha \text {-Oxoglutarate }+1.8 \mathrm{~mm}-\mathrm{NAD}+ \\
20 \text { mM-malonate }\end{array}$ & $4 \cdot 8$ \\
\hline $\begin{array}{l}\alpha-\text { Oxoglutarate + isocitrate }+ \\
1.8 \text { mM-NAD }+20 \text { mM-malonate }\end{array}$ & $15 \cdot 9$ \\
\hline
\end{tabular}

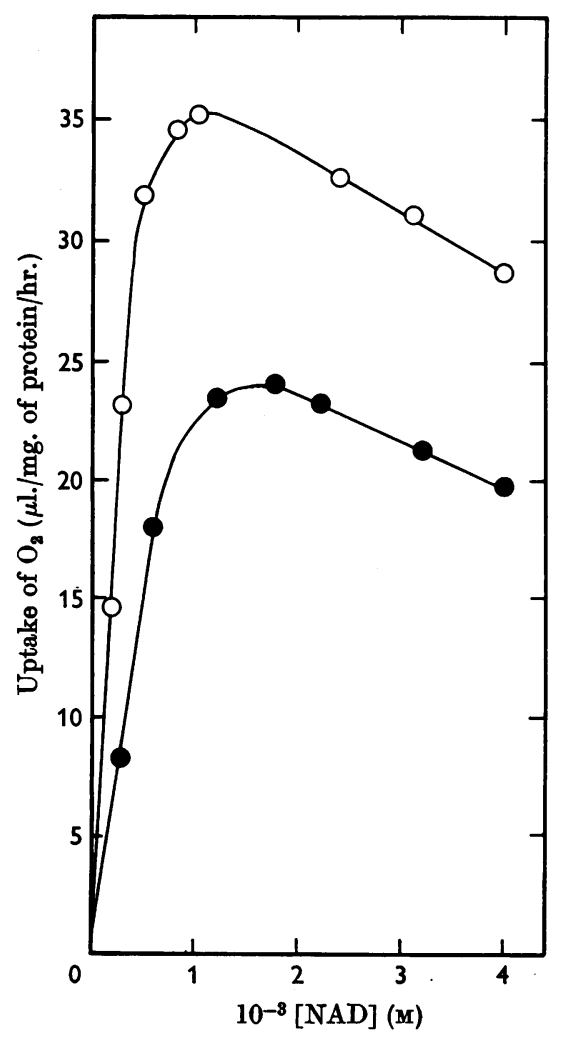

Fig. 10. Effect of concentration of NAD on the rate of isocitrate oxidation in pyridine nucleotide-depleted rat-liver mitochondria with oxygen as electron acceptor. The reaction medium was as described in Table 5. $0, \mathrm{~K}_{2} \mathrm{HPO}_{4}$ $\mathrm{KH}_{2} \mathrm{PO}_{4}$ buffer ( $\mathrm{pH} \mathrm{7 \cdot 4}$ ), $45 \mathrm{~mm}$; $O$, tris-acetate buffer (pH 7.4), 45 mM. Mitochondrial protein: $3.3 \mathrm{mg}$. (phosphate) and $4.2 \mathrm{mg}$. (tris-acetate)/flask. investigation, the effect of NAD concentration on isocitrate oxidation in rat-liver mitochondria was studied. Results presented in Fig. 10 show that in phosphate buffer the rate of oxygen uptake was maximal at $1.6 \mathrm{~mm}-\mathrm{NAD}$, whereas in tris-acetate buffer the maximal rate occurred at 1.2 mM-NAD. The rate of oxygen uptake was approx. $30 \%$ greater in tris-acetate than in phosphate buffer of the same $\mathrm{pH}$, when both systems were saturated with NAD.

Curves in Fig. 11 show the effect of added NADP on NAD + isocitrate oxidation in pyridine nucleotide-depleted rat-liver mitochondria. In phosphate buffer (pH 7.4) the addition of $0.51 \mathrm{~mm}$ NADP to a reaction medium containing isocitrate and 2.4 mM-NAD (i.e. at a concentration greater than the saturation level) increased $q_{\mathrm{o}_{3}}$ by approx. $100 \%$. Increase of the NADP concentration above the value of $0.51 \mathrm{~mm}$ failed to stimulate further the rate of oxygen uptake. In tris-acetate buffer,

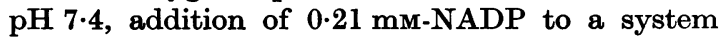
containing isocitrate and $1.54 \mathrm{~mm}-\mathrm{NAD}$ stimulated respiration to some extent (Fig. 11). In contrast with the results obtained in phosphate buffer, however, respiration in tris-acetate was not linear with time and began to decrease after $10 \mathrm{~min}$. Further results with the tris-acetate buffer system and oxygen as terminal acceptor are presented in Table 7. In a system saturated with NAD (1.54 mM),

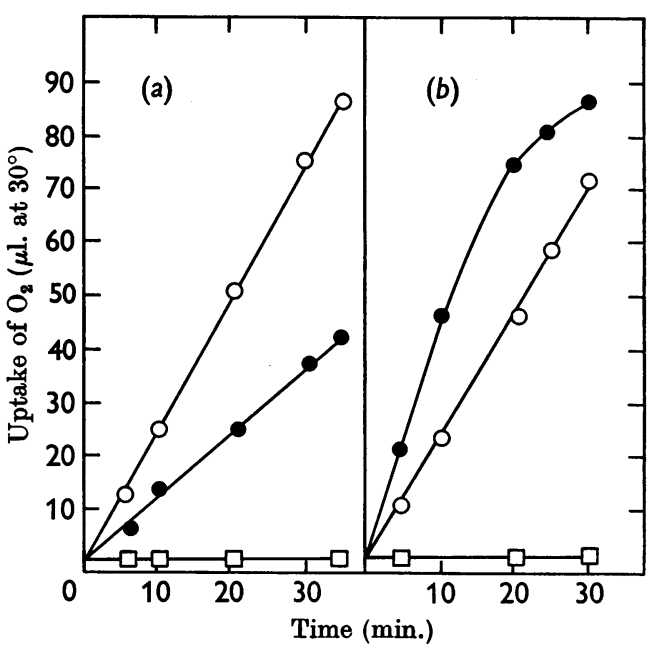

Fig. 11. Oxygen uptake of pyridine nucleotide-depleted rat-liver mitochondria with isocitrate as substrate in $(a)$ phosphate and $(b)$ tris-acetate buffers. Warburg vessels contained the basic medium of Table 5 , with these extra additions: $(a) \square$, no added cofactor; $0,1.80 \mathrm{mM}-\mathrm{NAD}$; O, 2.40 mM-NAD + 0.51 mM-NADP. (b) $\square$, no added cofactor; $O, 1.1 \mathrm{mM}-\mathrm{NAD}$; $0,1.54 \mathrm{mM}-\mathrm{NAD}+0.21 \mathrm{~mm}$ NADP. Mitochondrial protein content, $3.30 \mathrm{mg}$. (phosphate) and $4.2 \mathrm{mg}$. (tris-acetate). 
Table 7. Oxygen uptake of pyridine nucleotide-depleted rat-liver mitochondria in tris-acetate buffer

Manometric flasks contained the basic reaction medium of Table 5, with 45 mM-tris-acetate buffer (pH 7•4) replacing phosphate. Mitochondrial protein, $4 \cdot 2 \mathrm{mg}$. Equilibration time, $10 \mathrm{~min}$. Substrate, isocitrate.

Inhibition due

Special additions

$1 \cdot 54$ mM-NAD

1.54 mM-NAD +0.21 mM-NADP

$1.54 \mathrm{~mm}-\mathrm{NAD}+0.42 \mathrm{~mm}-\mathrm{NADP}$

$1.54 \mathrm{mM}-\mathrm{NAD}+1.27 \mathrm{mM}-\mathrm{NADP}$

1.54 mM-NAD + 8.0 mM-potassium phosphate ( $\mathrm{pH} 7 \cdot 4)$

1.54 mM-NAD + 24.0 mM-potassium phosphate $(\mathrm{pH} \mathrm{7 \cdot 4})$

1.54 mM-NAD + 48.0 mM-potassium phosphate ( $\mathrm{pH} \mathrm{7.4)}$

$\begin{array}{cc}q_{\mathrm{O}_{2}}\left(\mu \mathrm{l} . \text { of } \mathrm{O}_{2} / \mathrm{mg} .\right. & \text { to phosphate } \\ \text { of protein/hr.) } & (\%) \\ 0 \cdot 2^{*} & - \\ 34 \cdot 6^{*} & - \\ 65 \cdot 9^{*} & - \\ 56 \cdot 6^{*} & - \\ 50 \cdot 5^{*} & - \\ 35 \cdot 4 & 0 \\ 30 \cdot 1 & 15 \\ 22 \cdot 7 & 36\end{array}$

* $q_{\mathrm{O}_{2}}$ calculated from the respiration between 2 and 12 min., where the rate is linear.

addition of $0.21 \mathrm{~mm}$-NADP resulted in $q_{\mathrm{o}_{2}} 65.9$. When the concentration of NADP added was increased from 0.21 to 0.42 and $1.27 \mathrm{~mm}, q_{\mathrm{o}_{2}}$ decreased from 65.9 to 56.6 and 50.5 respectively (Table 7).

To try to determine the reason for the above difference in behaviour of addition of NADP and NAD in the phosphate and tris-acetate buffer systems, the effect of inorganic phosphate on isocitrate oxidation with NAD as cofactor was studied. The results in Table 7 show that, whereas addition of $8.0 \mathrm{~mm}$-phosphate to the system in tris-acetate buffer had no effect on oxygen uptake, increase of the phosphate concentration to $48 \mathrm{~mm}$ caused a $36 \%$ inhibition of respiration. This explains the lower rate of respiration observed in phosphate buffer in Fig. 10. Reasons for the falling off in the rate of respiration when both NADP and NAD served as cofactors for the oxidation of isocitrate in tris-acetate buffer (Fig. 10) are not known.

The effect of variation in $\mathrm{pH}$ on NAD-linked isocitrate oxidation with oxygen as terminal electron acceptor was studied in tris-acetate buffer. Results in Fig. 12 show that the maximum rate of oxygen uptake occurred at $\mathrm{pH} 7 \cdot 2$, with a steep fall in activity on either side of this value.

To test whether the NAD-dependent oxygen uptake by depleted rat-liver mitochondria was due to phosphorylation of NAD to NADP by ATP, as suggested by Vignais \& Vignais (1961), the experiments described in Table 8 were carried out. These show that $0 \cdot 1 \mathrm{~mm}-2,4$-dinitrophenol, a potent uncoupler of oxidative phosphorylation, was without effect on the respiration with NAD as cofactor. Also, the removal of the nucleotide acceptors ADP and AMP lowered the $q_{\mathrm{o}_{2}}$ only from 26.5 to $20 \cdot 2$, and addition of an active hexokinase gave similar results. These findings make it unlikely that phosphorylation of NAD to NADP by extramitochondrial ATP could have been responsible for the oxygen uptake with NAD as cofactor in our

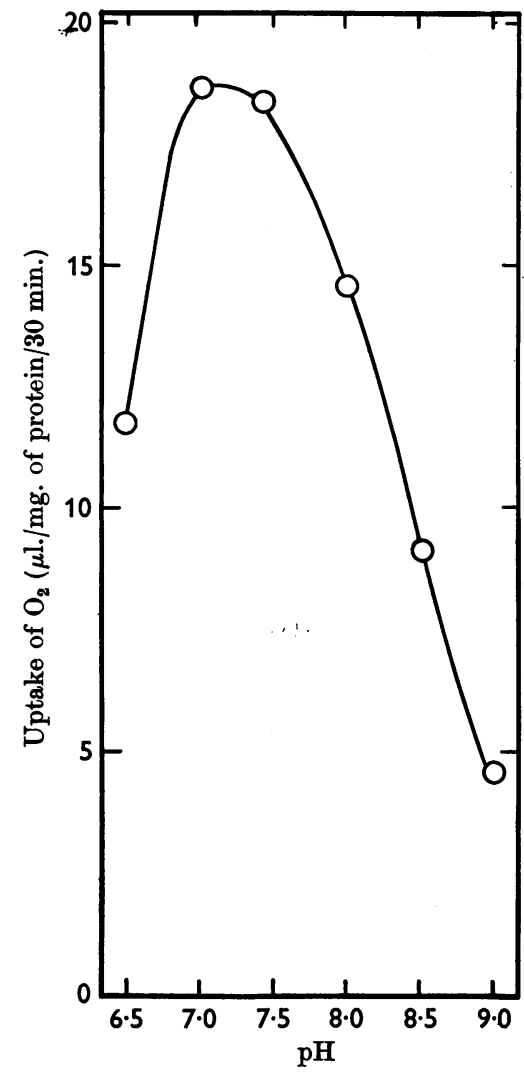

Fig. 12. Effect of $\mathrm{pH}$ on NAD-dependent isocitrate oxidation in depleted rat-liver mitochondria with oxygen as terminal electron acceptor. Reaction medium was as described in Table 5, with tris-acetate buffer (pH 7.4), $45 \mathrm{~mm}$, and NAD, $1.28 \mathrm{~mm}$. Mitochondrial protein, $6 \cdot 8 \mathrm{mg}$./flask.

experiments. The possibility of the presence of small amounts of intramitochondrial ATP, inaccessible to hexokinase and dinitrophenol, cannot, however, be entirely excluded. 
Effect of inhibitors on oxidation of isocitrate by rat-liver. The effect of electron-chain inhibitors on isocitrate oxidation with oxygen as electron acceptor was studied in the phosphate-buffered medium of $\mathrm{pH} \mathbf{7 \cdot 4}$, and the results are presented in Table 9. The inhibitors were preincubated with mitochondria for $10 \mathrm{~min}$. at room temperature before measurement of oxygen uptake. Amytal $(1.8 \mathrm{~mm})$ produced an inhibition of $47 \%$ in isocitrate oxidation with $0.8 \mathrm{mM}-\mathrm{NAD}$ as added co-

Table 8. Effect of 2,4-dinitrophenol and the absence of nucleotide acceptors on NAD-dependent isocitrate oxidation in pyridine nucleotide-depleted rat-liver mitochondria

The reaction medium was as described for Table 5. Each manometric vessel contained $10.5 \mathrm{mg}$. of mitochondrial protein. Reaction time, $20 \mathrm{~min}$.

System tested

Isocitrate (10 mM)

Isocitrate $+1.30 \mathrm{~mm}-\mathrm{NAD}$

$q_{\mathrm{O}_{2}}\left(\mu \mathrm{l}\right.$ of of $\mathrm{O}_{2} / \mathrm{mg}$.

2,4-dinitrophenol

Isocitrate + $\mathbf{1 . 3 0}$ mM-NAD minus ADP

26.0

and $A M P$

Isocitrate $+1 \cdot 30$ mM-NAD minus $\mathrm{ADP}$,

AMP and hexokinase factor, and $35 \%$ inhibition with $0.67 \mathrm{~mm}-\mathrm{NADP}$ and $0.8 \mathrm{~mm}-\mathrm{NAD}$ as added cofactors. Antimycin A (6 $\mu$ g.) inhibited oxidation (by $48 \%$ ) with NAD as coenzyme and by $22 \%$ when both NAD and NADP were present as coenzymes.

Neotetrazolium chloride as electron acceptor. The results described above have demonstrated that normal rat-liver mitochondria are capable of oxidizing isocitrate with either NAD or NADP + NAD as cofactor, and that the oxidations are followed apparently by electron transfer via separate cytochrome pathways to oxygen. How ever, all attempts to show the presence of a NAD. linked isocitrate dehydrogenase failed. These included measurement of reduced NAD production at $340 \mathrm{~m} \mu$ and the use of either 2,6-dichlorophenolindophenol or cytochrome $c$ as electron acceptor. In an attempt to demonstrate indirectly the formation of reduced NAD by the NAD-dependent isocitrate dehydrogenase, experiments with neotetrazolium chloride as electron acceptor were carried out.

The results are presented in Table 10. Pyridine nucleotide-depleted mitochondria did not reduce the dye in the absence of added cofactor. However, with NAD as added coenzyme, reduction of the dye occurred, and this was increased in the

Table 9. Effect of electron-chain inhibitors on isocitrate oxidation in pyridine nucleotide-depleted rat-liver mitochondria with oxygen as acceptor

The reaction medium in each manometric flask was as described for Table 5. Mitochondrial protein, $4.93 \mathrm{mg}$.; Amytal (sodium salt), $1.8 \mathrm{~mm}$; antimycin A (in $96 \%$ ethanol), $6 \mu \mathrm{g}$. Mitochondria were preincubated with inhibitors for $10 \mathrm{~min}$. at room temperature before measurement of oxygen uptake. Equilibration time, $10 \mathrm{~min}$.

\begin{tabular}{|c|c|c|}
\hline System & $\begin{array}{c}q_{\mathrm{o}_{2}}\left(\mu \mathrm{l} . \text { of } \mathrm{O}_{2} / \mathrm{mg} \text {. }\right. \\
\text { of protein } / \mathrm{hr} \text {.) }\end{array}$ & $\begin{array}{c}\text { Inhibitio } \\
(\%)\end{array}$ \\
\hline Isocitrate & - & - \\
\hline Isocitrate $+0.80 \mathrm{mM}-\mathrm{NAD}$ & $12 \cdot 7$ & \\
\hline Isocitrate $+0.80 \mathrm{mM}-\mathrm{NAD}+$ Amytal & $6 \cdot 7$ & $\mathbf{4 7 \cdot 3}$ \\
\hline Isocitrate $+0.80 \mathrm{mM}-\mathrm{NAD}$ + antimycin $\mathrm{A}$ & $6 \cdot 6$ & $48 \cdot 1$ \\
\hline Isocitrate $+0.67 \mathrm{mM}-\mathrm{NADP}+0.80 \mathrm{mM}-\mathrm{N} A \mathrm{D}$ & $23 \cdot 4$ & \\
\hline Isocitrate $+0.67 \mathrm{mM}-\mathrm{NADP}+0.80 \mathrm{mM}-\mathrm{NAD}+$ Amytal & $15 \cdot 1$ & $35 \cdot 5$ \\
\hline Isocitrate $+0.67 \mathrm{~mm}-\mathrm{NADP}+0.80 \mathrm{mM}-\mathrm{NAD}+$ antin & $18 \cdot 3$ & $21 \cdot 8$ \\
\hline
\end{tabular}

Table 10. Reduction of neotetrazolium chloride by pyridine nucleotide-depleted rat-liver mitochondria

Each reaction tube contained, in a final volume of $1.7 \mathrm{ml}$. : tris-acetate buffer (pH 7.4), $55 \mathrm{~mm}$; nicotinamide, $22 \mathrm{mM} ; \mathrm{MgCl}_{2}, 1.6 \mathrm{mM}$; neotetrazolium chloride, $1.5 \mathrm{mg}$.; KCN, $0.8 \mathrm{mM}$; DL-isocitrate (potassium salt, $\mathrm{pH} \mathrm{7.4)}$ ), $2.7 \mathrm{mM}$; DL- $\beta$-hydroxybutyrate, $0.27 \mathrm{mM}$; vitamins $\mathrm{K}_{1}$ and $\mathrm{K}_{3}$ were added as suspensions in ethanol-phosphateplasma albumin (prepared as described by Slater, 1959). Mitochondrial protein content, $0.73 \mathrm{mg}$. Reaction time, $30 \mathrm{~min}$. Temperature, $30^{\circ}$.

System

Isocitrate

Isocitrate $+0 \cdot 20 \mu$ mole of NAD

Isocitrate $+0.20 \mu$ mole of NAD $+0.30 \mu$ mole of vitamin $\mathrm{K}_{3}$

Isocitrate $+0.20 \mu$ mole of NAD $+0.20 \mu$ mole of vitamin $K_{1}$

Isocitrate $+0.20 \mu$ mole of NADP

Isocitrate $+0.20 \mu$ mole of NADP $+0.25 \mu$ mole of NAD

$\beta$-Hydroxybutyrate $+0.20 \mu$ mole of NAD
$E_{510 m \mu}$ (electron acceptor, neotetrazolium chloride)

$\overbrace{\text { Minus cyanide }}^{\text {Plus cyanide }}$

0.110

-

$0 \cdot 220$

0.080

$0 \cdot 143$

0.532
$0 \cdot 138$

0.008

$\mathbf{0 . 2 3 5}$

0.086

0.166

0.718 
presence of 0.8 mM-cyanide. Vitamin $K_{1}(0.2 \mu$ mole $)$ stimulated the reduction twofold, whereas vitamin $\mathrm{K}_{3}(0.2 \mu \mathrm{mole})$ inhibited dye reduction almost completely. Isocitrate oxidation with NADP as cofactor also caused some reduction of neotetrazolium chloride, the rate being hardly affected by the addition of cyanide.

\section{DISCUSSION}

The present work on isocitrate oxidation in normal rat-liver mitochondria with oxygen as electron acceptor has provided evidence for the presence in these particles of two pathways for such oxidation (Fig. 13). One of the pathways, that containing the sequence NADP-specific isocitrate dehydrogenase $\rightarrow$ transhydrogenase $\rightarrow$ $\mathrm{NADH}_{2} \rightarrow$ oxygen has been assumed by both Kaplan et al. (1956) and Purvis $(1958 a, b)$ to be the only one available for isocitrate oxidation in ratliver mitochondria. Kaplan based this conclusion on experimental results with 2,6-dichlorophenolindophenol, cytochrome $c$ and oxygen as electron acceptors, employing mitochondria not completely depleted of endogenous pyridine nucleotides. Purvis used completely depleted mitochondria but reported experimental findings only with 2,6dichlorophenol-indophenol as electron acceptor. The finding that this pathway comprises approximately $50 \%$ of the total isocitrate-oxidase activity is based on work with carefully depleted mitochondria and a study of the effects of cofactor concentration on oxygen uptake.

The second pathway for isocitrate oxidation has been found to be NAD-dependent (Fig. 13). This route for isocitrate oxidation has been established by Ernster (1959) and Ernster \& Glasky (1960), but their results differ from those of the present work in that only $50 \%$ of the total isocitrate-oxidase activity of intact mitochondria when NAD was added in saturating amounts to pyridine nucleotidedepleted mitochondria has been accounted for. Ernster's group, however, obtained complete restoration of isocitrate oxidation with added NAD. The difference between the present results and those of Ernster (1959) may be due to differences in the preparation and depletion of the mitochondria, since Ernster \& Glasky (1960) showed

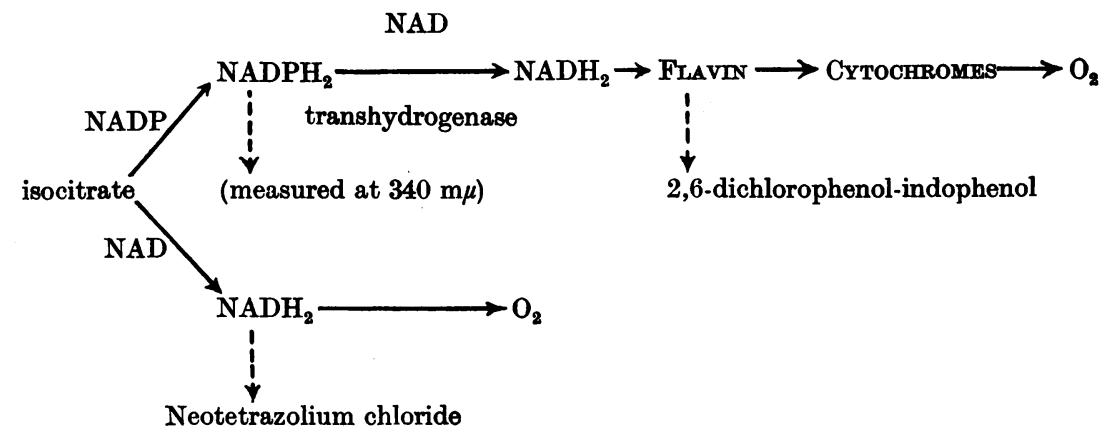

(a)

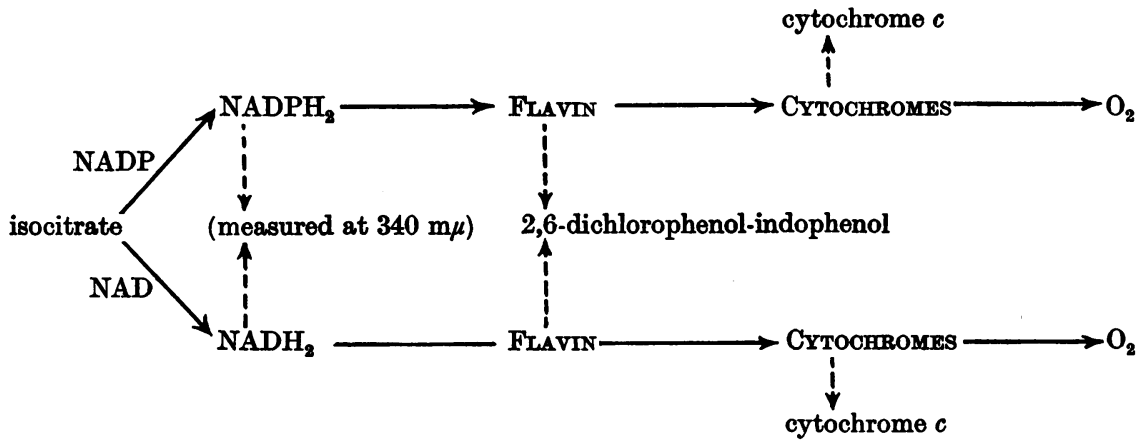

(b)

Fig. 13. Isocitrate oxidation by (a) mitochondria of hepatomas induced by feeding with 4-dimethylamino-3'methylazobenzene and 4-dimethylaminoazobenzene and $(b)$ mitochondria of the Ehrlich ascites tumour. 
that the ability of their mitochondria to oxidize citrate depended on the method of depletion used. Mitochondria prepared by their usual method oxidized citrate, in contrast with those used in the present work, which were unable to do so.

Vignais \& Vignais (1961) also found that NAD can support isocitrate oxidation in depleted ratliver mitochondria and provided evidence suggesting the phosphorylation of NAD to NADP by either added ATP or ATP generated by oxidative phosphorylation, thus permitting the NADPlinked dehydrogenase-transhydrogenase pathway to operate. This explanation, however, disagrees with the findings that depleted rat-liver mitochondria will oxidize isocitrate with added NAD as cofactor in the absence of added ADP or AMP, and that oxygen uptake is unaffected when 2,4-dinitrophenol is present to uncouple phosphorylation.

The NAD-linked pathway could be clearly demonstrated only with oxygen as terminal electron acceptor. In agreement with Stein, Kaplan \& Ciotti (1959), Purvis $(1958 a, b)$ and Vignais \& Vignais (1961), it was found that added NAD was not reduced with isocitrate as substrate by depleted mitochondria under a variety of conditions. These involved the use of Amytal, antimycin $A$ and azide as inhibitors of electron transport in preference to cyanide, which has been shown by Plaut \& Sung $(1954,1955)$ to be inhibitory towards a NAD-linked isocitrate-dehydrogenase enzyme in acetone-dried powders of pig and rat livers. Also the treatment of mitochondria with various detergents failed to demonstrate the presence of a NADlinked dehydrogenase. Some success, however, in indirectly demonstrating $\mathrm{NADH}_{2}$ production by the NAD-linked pathway was achieved with neotetrazolium chloride as electron acceptor.

Hepatoma mitochondria. Mitochondria from hepatomas induced by the azo dyes 4-dimethylamino-3'-methylazobenzene and 4-dimethylaminoazobenzene possess both NAD- and NADP-linked isocitrate-dehydrogenase systems. In contrast with normal liver mitochondria, isocitrate oxidation by the hepatoma mitochondria with NAD as cofactor could be demonstrated at the dehydrogenase level and with 2,6-dichlorophenol-indophenol and oxygen as electron acceptors (Fig. 13).

The above results parallel those obtained with mitochondria of the Ehrlich ascites tumour (Hawtrey \& Silk, 1960, 1961), and indicate that certain tumour mitochondria possess a pathway for isocitrate oxidation which is clearly different from that of normal liver.

The increase in activity of NAD-dependent isocitrate oxidation in certain tumour mitochondria (Hawtrey \& Silk, 1960, 1961) may be related to the low concentration of pyridine nucleotides, particularly of NADP, in tumours (Wenner \& Wein- house, 1953; Glock \& McLean, 1957 ; Briggs, 1960; Borst \& Colpa-Boonstra, 1960), and to the disappearance of the transhydrogenase enzyme (WilliamsAshman, 1953; Reinaforje \& Potter, 1957; Hawtrey \& Silk, 1960). This suggests that the efficiency of the tricarboxylic acid cycle would be impaired at the stage of isocitrate dehydrogenation were it not for an increase in NAD-dependent enzyme activity.

\section{SUMMARY}

1. Rat-liver mitochondria possess both NADPand NAD-linked isocitrate-oxidase systems. The NADP-dependent system, which is linked via a transhydrogenase enzyme to oxygen, can be demonstrated with a number of electron acceptors and oxygen. On the other hand, the NAD-linked isocitrate system can only be detected with oxygen and neotetrazolium chloride as the terminal electron acceptors.

2. In a phosphate-buffered medium with oxygen as electron acceptor, both the NAD- and NADP. linked systems show equal activity, and, furthermore, the sum of these activities in pyridine nucleotide-depleted mitochondria saturated with added pyridine nucleotide is equal to the activity in intact mitochondria.

3. Mitochondria of rat-liver hepatomas induced by feeding with 4-dimethylamino-3'-methylazobenzene and 4-dimethylaminoazobenzene possess both NAD- and NADP-linked isocitrate-dehydrogenase systems.

4. In contrast with the results obtained on the NAD-linked isocitrate-dehydrogenase system of normal rat-liver mitochondria, activity associated with this enzyme system in the tumour mitochondria could be demonstrated at the dehydrogenase level or with 2,6-dichlorophenol-indophenol as electron acceptor.

5. Mitochondria of the 4-dimethylamino-3'methylazobenzene-induced tumour stored for $168 \mathrm{hr}$. at $0^{\circ}$ lose $47 \%$ of their NAD-linked isocitrate-diaphorase activity, whereas NADP-diaphorase activity is enhanced by $47 \%$.

The author is indebted to Dr H. M. Schwartz for helpful discussion, to Mr J. Dijkstra for providing rats containing the 4-dimethylamino-3'-methylazobenzene-induced hepatoma, and to Mr C. A. Schoeman and Miss V. Schirren for assistance. Thanks are also due to $\mathbf{M r}$ J. J. Dreyer and staff of the National Nutrition Research Institute, Pretoria, and Professor J. Gillman of the University of the Witwatersrand for providing certain of the animals used in this work.

\section{REFERENCES}

Briggs, M. H. (1960). Nature, Lond., 187, 249.

Borst, P. \& Colpa-Boonstra, J. P. (1960). Biochem. J. 76, $60 \mathrm{P}$. 
Ciotti, M. M. \& Kaplan, N. O. (1957). In Methods in Enzymology, vol. 3, p. 890. Ed. by Colowick, S. P. \& Kaplan, N. O. New York: Academic Press Inc.

Cleland, K. W. \& Slater, E. C. (1953). Biochem. J. 53, 547.

Dounce, A. L., Witter, R. F., Monty, K. J., Pate, S. \& Cottone, M. A. (1955). J. biophys. biochem. Cytol. 1, 139.

Ernster, L. (1959). Symp. biochem. Soc. 16, 54.

Ernster, L. \& Glasky, A. J. (1960). Biochim. biophys. Acta, 38, 168.

Glock, G. E. \& McLean, P. (1957). Biochem. J. 65, 413.

Hawtrey, A. O. \& Silk, M. H. (1960). Biochim. biophys. Acta, 37, 185.

Hawtrey, A. O. \& Silk, M. H. (1961). Biochem. J. 79, 235.

Kaplan, N. O., Colowick, S. P. \& Neufeld, E. F. (1953). J. biol. Chem. 205, 1.

Kaplan, N. O.. Swartz, M. N., Frech, M. E. \& Ciotti, M. M. (1956). Proc. nat. Acad. Sci., Wash., 42, 481.
Miller, E. C. \& Miller, J. A. (1948). J. exp. Med. 87, 139.

Plaut, G. W. E. \& Sung, S. C. (1954). J. biol. Chem. 207, 305.

Plaut, G. W. E. \& Sung, S. C. (1955). In Methods in Enzymology, vol. 1, p. 710. Ed. by Colowick, S. P. \& Kaplan, N. O. New York: Academic Press Inc.

Purvis, J. L. (1958a). Biochim. biophys. Acta, 30, 440.

Purvis, J. L. (1958b). Nature, Lond., 182, 711.

Purvis, J. L. (1960). Biochim. biophys. Acta, 38, 435.

Reinaforje, B. \& Potter, V. R. (1957). Proc. Amer. Ass. Cancer Res. 2, 241.

Slater, T. F. (1959). Biochem. J. 73, 314.

Stein, A. M., Kaplan, N. O. \& Ciotti, M. M. (1959). J. biol. Chem. 234, 979.

Vignais, P. V. \& Vignais, P. M. (1961). Biochim. biophys. Acta, 47, 515.

Wenner, C. E. \& Weinhouse, S. (1953). Cancer Res. 13, 21. Williams-Ashman, H. G. (1953). Cancer Res. 13, 721.

Biochem. J. (1962) 85, 305

\title{
Occurrence and Distribution of Methylated Purines in the Ribonucleic Acids of Subcellular Fractions
}

\author{
By P. L. BERGQUIST* AND R. E. F. MATTHEWS $\dagger$ \\ Plant Diseases Division, Department of Scientific and Industrial Research, Auckland, New Zealand
}

(Received 13 February 1962)

Until recently only two purine and two pyrimidine bases had been found in RNA. The first evidence that other components might be present was provided by the isolation of the nucleotide of 5-ribosyluracil (Cohn, 1957, 1958, 1960; Davis \& Allen, 1957; Scannell, Crestfield \& Allen, 1959). Cohn reported that in the course of the isolation of 5-ribosyluracil nucleotide he had observed other substances that appeared to be adenine derivatives with methyl groups on the C-2 or 6-amino positions of the purine ring. Adler, Weissman \& Gutman (1958) detected a number of methylated purines in acid hydrolysates of yeast RNA. A careful study of RNA from a number of plant, animal, bacterial and viral sources has since led to the isolation of 2-methyladenine, 6-methylaminopurine, 6-dimethylaminopurine, 1-methylguanine, 6-hydroxy2-methylaminopurine and 6-hydroxy-2-dimethylaminopurine (Littlefield \& Dunn, 1958; Dunn \& Smith, 1959). Smith \& Dunn (1959) provided evidence for the occurrence of the methylated purines as true RNA components in $3^{\prime}, 5^{\prime}$-phosphodiester linkage.

\footnotetext{
* Present address: John Collins Warren Laboratories, Huntington Memorial Hospital of Harvard University at the Massachusetts General Hospital, Boston, Mass., U.S.A.

$\dagger$ Present address: Microbiology Department, University of Auckland, New Zealand.
}

Dunn (1959) showed that there was a substantially higher proportion of methylated purines in the soluble RNA fraction of rat liver than in the microsomes. We have confirmed and extended this observation for several plant and animal tissues. The RNA in the soluble fraction of all tissues examined is much richer in these bases than is either microsomal or mitochondrial RNA. The portion of the soluble RNA that remains in solution at $\mathrm{pH} 5.2$ is richer in methylated purines than is the fraction that is precipitated. We put forward the suggestion, based on calculations from our data, that all the methylated purines may in fact occur in soluble RNA, and that those found in particulate fractions are there because of the soluble RNA which was functionally associated with the particles at the time of their isolation. A preliminary account of some of this work has already appeared (Bergquist \& Matthews, 1959).

\section{MATERIALS AND METHODS}

Chemicals. Samples of 6-amino-2-methylpurine, 6methylaminopurine, 6-dimethylaminopurine, 6-methylaminopurine riboside, 2-amino-6-hydroxy-1-methylpurine, 6-hydroxy-2-methylaminopurine, 6-hydroxy-2-dimethylaminopurine, were generously donated by Dr J. D. Smith. Further samples of 6-methylaminopurine, 6-dimethylaminopurine, 2-amino-6-hydroxy-1-methylpurine and 6- 